\title{
Creating and Evolving an Open Innovation Ecosystem: Lessons from Symbian Ltd.
}

\author{
Joel West* \\ College of Business, San José State University \\ San José, CA 95192-0070 USA \\ Joel.West@sjsu.edu \\ David Wood \\ Research \\ Symbian Ltd. \\ London SE1 8HP, U.K. \\ david.wood@symbian.com
}

11 July 2008

*Corresponding author

\begin{abstract}
Firms that practice open innovation strategies rely on the cooperation of external firms to provide components, complements and customers for the innovations of the focal firm (Chesbrough, 2003). Such strategies can be quite complex in systems-based industries, which inherently require coordinating across a wide range of partners to deliver customer value (West, 2006).

Open innovation researchers have theorised that value networks (or business ecosystems) can play an important part in such open innovation strategies (Vanhaverbeke, 2006; Maula et al, 2006). However, limited empirical work has been done on the process of creating such ecosystems and the forces and processes that cause them to evolve over time.

In considering firm ecosystem strategies, we are interested in the linkage between firm motivations, ecosystem strategies and outcomes, and how these factors and their relationships evolve over time. To do so, we examine the complex ecosystem surrounding Symbian Ltd. that supports its mobile phone operating system.

After reviewing prior research on open innovation networks, we present a longitudinal case study on the creation and evolution of Symbian's ecosystem over three distinct phases in its first decade. From this, we identify inherent challenges of managing open innovation networks, including creating a new network for an unproven value proposition, and prioritising the conflicting needs of disparate network members.
\end{abstract}

Keywords: value networks, ecosystems, open innovation, mobile phones 


\section{Creating and Evolving an Open Innovation Ecosystem: Lessons from Symbian Ltd.}

\section{INTRODUCTION}

Certain classes of complex products are created through the integration of a range of components and technologies. Producing such products in an open innovation context depends on contributions from across a network of suppliers of components and complements that create value for the eventual buyer. For a brand new product — or one that must be kept up to date by incorporating an ongoing stream of technological advances — this coordinated innovation by network members requires leadership of the network to deliver the systems product and its complements (Prencipe et al, 2003; Maula et al, 2006; West, 2006).

One such complex product is a mobile phone, of which more than 1 billion are sold each year (Zeman, 2008). Compared to a less popular (but more often studied) systems product — the personal computer — the mobile phone has a wider range of component suppliers and a more complex distribution system.

Here we study the open innovation network organised around a specific category of mobile phones, those incorporating the Symbian operating system, which accounted for twothirds of the 115 million advanced mobile phones sold in 2007 (Canalys, 2008). Starting from Symbian's founding in 1998, we map the dynamic nature of Symbian's “ecosystem" management strategy across three distinct phases over its first decade.

In particular, we demonstrate how Symbian governed its ecosystem not through absolute market power, but through access to non-public information and contractual restrictions on the use of its intellectual property. We show how Symbian developed an emergent ecosystem management strategy, in which its formal ecosystem program represented a lagging indicator of Symbian's changing conception of how value was created in the ecosystem. 
After review of prior research on networks in innovation, we provide a brief summary of Symbian's structure and context, and then use that to trace the evolution of Symbian's formal ecosystem strategy through three distinct phases. From this we make suggestions for contributions to theories of ecosystem governance and future research.

\section{Managing Open Innovation Networks}

Our study builds upon prior research on value networks, ecosystems and their role in open innovation strategies. Here we use them to develop research questions about the creation and evolution of such networks.

The term "value chain" has been used to refer to the business relationships along a path from the supplier of raw materials through intermediate producers to the ultimate end-users (Porter, 1985: 33-39). However, many products increase in value through the provision of complementary products, and these complementary products are often supplied to users by third parties outside the value chain (Teece, 1986). Such complements are particularly important with information technology platforms, where standardized interfaces are defined and disseminated to encourage the production of complements (Gawer \& Henderson, 2007).

When such complementary products are considered in combination with the value chain the resulting relationships are often termed a "value network" (e.g. Amit and Zott, 2001) or an “ecosystem" (Iansiti and Levien, 2004). ${ }^{1}$ Such networks have been recognised as an important part of open innovation cooperation in certain industries (e.g., Chesbrough, 2003: 68; Maula et al, 2006; Vanhaverbeke and Cloodt, 2006). The efficiency and effectiveness of cooperation between network member firms is often facilitated through the use of information technologies (Dodgson et al, 2006).

1 Here we use the two terms interchangeably, but favour "ecosystem" in the explanation because it is the one used by the subjects of our study. 
The practice of what today is called ecosystem management predates formal academic theory on the subject, particularly in computer systems. From the birth of the mainframe application software business with IBM's 1969 unbundling decision ${ }^{2}$ through the sale of retail packaged software such as Visicalc for personal computers a decade later, system vendors have increasingly recognised the importance of third party-complements for the success of their products (Campbell-Kelly, 2003). Beginning in 1983, Apple Computer even created a new job category called "evangelist" to attract new ecosystem member companies and to coordinate interactions with the ecosystem sponsor (Kawasaki, 1990).

Prior research has emphasised the importance that certain firms play in leading or guiding such a business ecosystem. An ecosystem typically contains a high rate of interdependency among member firms, and the member firms normally benefit from any value-creating member of the ecosystem (Iansiti and Levien, 2004). Such cooperation may depend on the provision of well defined interfaces or other technical standards that facilitate coordination and cooperation between member companies (Johnson, 2003).

Among ecosystem member firms, certain firms are well-situated to play a crucial role in linking members of the ecosystem and catalyzing links between other members. As such, these firms are often best situated to capture a disproportionate share of benefits created by the ecosystem (Normann and Ramirez, 1993; Iansiti and Levien, 2004; Maula et al, 2006).

However, empirical and field studies of open innovation network management have tended to present the established ecosystem strategies of central firms in terms of post hoc rationalisation, rather than identify the means by which ecosystem strategies emerge from the goals and initial experiments of member firms. In addition, most studies have considered the

2 IBM's 1969 decision (fearing antitrust regulation) to sell its mainframe hardware and software separately effectively substituting open innovation for vertical integration — is today credited as being a key turning point in created a market for stand-alone software products (Steinmueller, 1996). 
ecosystem strategies of firm(s) at a single point in time rather than the interdependency of evolving strategic choice and context.

Here we are interested in two broad research questions about how an ecosystem is created and evolves that we believe are not addressed by previous research. Our first question is where does an ecosystem come from: Is it created by the ecosystem leader, or merely a tacit recognition of pre-existing industry structure? Is the ecosystem defined by economic relations, or by the cognitive construction of the ecosystem participants (as with Reger and Huff's 1993 cognitive model of strategic groups)?

Secondly, how do ecosystems evolve over time? Does it reflect forethought and intentional shaping of the ecosystem as suggested by Maula and his colleagues (2006)? Or, rather than such an intentional strategy, does the ecosystem evolution reflect an emergent strategy (to use Mintzberg's 1978 typology)?

\section{Research Design}

Our study uses a case study research design, which is widely accepted as a way to understand and explain complex interorganisational relationships to develop theoretical insights (e.g., Eisenhardt, 1989).

Here we study the ecosystem of Symbian Ltd., a privately held London-based developer of a mobile phone operating system for advanced mobile phones that it termed "smartphones." Unlike the vertically-integrated strategies used for the earliest mobile phone production, Symbian's business model of selling its software to a wide range of manufacturers anchored it explicitly within the open innovation paradigm.

We compiled data regarding changes in the company's ecosystem from a wide range of primary and secondary sources. Primary data from Symbian includes current information on its website, archived press releases dating to 1998 that are still published on the website, and previous information from the company website stored on the Internet Archive (Archive.org). 
We have also referenced unpublished company memos and presentations, particularly around the evolution of the company's formal ecosystem program during each of its phases. We conducted interviews with current and former Symbian employees who managed aspects of its ecosystem strategy spanning the entire period $1998-2008 .{ }^{3}$ We were also guided by participant observation by one of the authors, who was directly involved in the second phase of the ecosystem program.

Finally, we have been able to supplement our data with secondary data on the company and its ecosystem. We drew upon news coverage, particularly in The Register, a UK-based IT journal; and summaries of the company's history and strategy in books by Symbian authors (e.g. Tasker, 2000; Wood, 2005; Northam, 2006).

\section{Symbian LTD. AND ITS StRUcture}

Symbian's smartphone ecosystem strategy shared important characteristics with those for the better known (and oft-studied) PC platform. In 2007, approximately 77 million new phones shipped with Symbian's operating system, as opposed to 250 million new PCs with Microsoft Windows. However, Windows PC shipments were nearly flat, while Symbian had averaged more than 50\% annual growth from 2002-2007 (Figure 1).

Like other operating system companies, Symbian seeks to maximise the supply of software supplied by third parties and thus the value created by that software. (Cf. Shapiro \& Varian, 1999). At the same time, as with any platform it must trade off advancing the OS characteristics against providing continuity of interfaces for such software.

Symbian's ecosystem has some interesting differences that facilitate comparison to the PC ecosystem. While the Windows ecosystem gradually emerged during the period 1981-1991,

3 The interviewees were Simon East, VP of Technology from 1998-2001; David Wood, head of Symbian Platinum Partners from 2002-2004; Alan Roderick, head of the Symbian Competency Centers from 20012004 and the Platinum program from 2004-2007; and Patricia Correa, who succeeded Roderick, developing and launching the Symbian Partner Network program in 2008. 
Symbian created an ecosystem strategy even before it shipped its first product, a strategy that evolved across three distinct phases in its first decade. Without Microsoft's market share and control of key applications, Symbian has less potential to impose monopoly power. In fact, the management of the Symbian ecosystem is constrained by the complexities of complements, systems architecture, distribution and ownership relations not present in better known computing architectures.

\subsection{PDA Heritage}

Symbian Ltd. was founded as a spinoff of another London-based company, Psion PLC, but was co-owned and funded by the world's largest handset makers (see Table 1 for key dates) ${ }^{4}$

Psion itself was founded in 1980 as a company developing software applications for a range of personal computers, including the Sinclair ZX80. Psion soon shifted to developing a family of keyboard-based pocket computer systems: Organiser I (1984), Organiser II (1986), Series 3 (1991) and Series 5 (1997). The latter two products used miniaturised QWERTY keyboards, and became part of became a product category called "personal digital assistants" (PDA), which also included Japan's Sharp Zaurus (launched in 1993), and from the US, the Palm Pilot (1996) and various "Handheld PC's" based on Microsoft's Windows CE (19961997).$^{5}$

Psion's Series 5 was designed around EPOC, the 32-bit PDA operating system it had developed. To attract a broader range of EPOC-enabled devices, in June 1996 Psion separated its software group into a separate company, Psion Software, and sought to license the

\footnotetext{
$4 \quad$ The history of Symbian and its relationship to Psion can be found in Tasker (2000) and Northam (2006).

5 Here we focus on the pocket-sized PDAs that eventually proved to the be dominant design for the product category, rather the unsuccessful, tablet-sized PDAs such as the Apple Newton (1992-1997) and AT\&T EO (1993-1994) that first gave the name to the category.
} 
software more broadly. That same year, Nokia shipped its first PDA type phone built upon software licensed from Geoworks Inc.

\subsection{Birth of the Smartphone}

From 1996 to early 1998, Psion Software held licensing discussions with the world's largest handset makers. In June 1998, Psion, Nokia and Ericsson announced that they would be joint owners of a new company, Symbian Ltd., and four months later Motorola bought a stake in Symbian.

Symbian was founded as an independent company by approximately 160 employees transferred from Psion Software. With the exception of Psion, Symbian's shareholders were mobile phone makers that were also its customers. While the company was established with equal shareholdings among two (soon three) mobile handset makers, the ownership structure changed over time as new Symbian manufacturer licensees acquired shares, and shares were sold or transferred as the result of manufacturer mergers and acquisitions (Table 2).

Symbian's founding purpose was to license the EPOC operating system for the world's leading handset makers to produce what Symbian eventually called "smartphones." Beyond the ability to make voice calls on the European-developed GSM mobile phone networks, these phones inherited the capabilities of Psion's organisers (such as calendar and address book), to which Symbian and its partners added features suitable for a mobile Internet device (such as e-mail and web browsing).

In 2000, Ericsson shipped the first Symbian-enabled phone, the R380. Nokia followed in 2001 when its second generation "communicator" product, the 9210, was built upon Symbian OS. The major PDA competitors to EPOC also began licensing their operating systems for phone use, first in 1999 with Palm OS and then a series of Windows CE products in 2001 and 2002. 
Symbian had designed its operating system to make it easy to change the user interface "look and feel" to allow its customers to offer distinctive products. It planned to develop a family of user interfaces for its OS, but over time its European customers migrated to two interfaces: Series 60, developed internally by Nokia for its own Symbian-enabled phones, and UIQ, a user interface originally developed by Symbian but which (as of late 2007) was owned equally by Sony Ericsson and Motorola. In Japan, the largest mobile phone carrier NTT DoCoMo owned a third user interface, MOAP-S, which provided a common user interface for Symbian OS phones sold to DoCoMo customers (Yoshizawa et al, 2006).

Over time, the competitive threat from Palm faded, but phones licensing Windows Mobile and vertically integrated smartphones from Research in Motion (the Blackberry) and Apple (the iPhone) continued to grow in sales, particularly in North America. A new platform competitor also emerged built upon open source software. As early as 2001, handset makers had expressed interest in using the Linux operating system. In 2007 two nonprofit consortia were formed to standardise and promote Linux handsets: the LiMo Foundation (initiated by British operator Vodafone) and the Open Handset Alliance (created by Google).

By the end of 2007, smartphones had grown to about $10 \%$ of all handsets sold worldwide; the remaining $90 \%$ of the phones sold were divided between "feature phones" and "entry level phones." Symbian OS was estimated to account for $65 \%$ of all smartphones - well ahead of Windows (12\%), the Research in Motion Blackberry series (11\%), Apple's iPhone $(6.5 \%)$ and Linux (5\%). Nokia alone held about $53 \%$ of the global smartphone market, or about $80 \%$ of all handsets utilising the Symbian OS (Canalys, 2008).

\section{Symbian's Evolving Ecosystem Strategy}

When Symbian began life in 1998, it had an established technology base for mobile devices, a team of experienced engineers and managers, and support from the three largest 
handset makers. At the same time, it faced a number of crucial challenge of building an ecosystem that would support its technological innovation.

It entered a new category of devices known variously as PDA phones or smartphones. Despite its inheritance from Psion, it was a new firm that eventually needed a new ecosystem. For both reasons, its managers did not know what sort of ecosystem would be required: like its competitors, it assumed that smartphone ecosystems would be similar to those for PDAs.

As its technology grew more popular, it attracted a growing number of potential ecosystem members, each wanting attention to solve their particular problems. At the same time, it was a small and (for the first seven years) money-losing company with limited resources. Thus, a crucial challenge was prioritising its scarce resources to build an ecosystem of unknown characteristics.

Finally, it faced two immediate competitors in Microsoft and Palm, at least three major future competitors largely unknown in 1998 - as well as many indirect competitors (i.e., the in-house software capabilities of its potential customers). Thus, as with most software companies, the intellectual property of its software copyrights and trade secrets were its major assets and it worried about leakage of that IP to existing or potential competitors (cf. Cusumano, 2004). As it turns out, these IP concerns coloured (and, in fact, hindered) its willingness to transfer knowledge to ecosystem members, and thus its ability to attract new members and to help them create value.

\subsection{Symbian's Ecosystem: Overview}

Symbian OS was only available to phone users pre-installed in a newly purchased Symbian-enabled phone. This meant that unlike a PC, Symbian could not sell end-user 
software upgrades and had effectively no direct relationship with customers. ${ }^{6}$ Instead, adoption of its latest technology depended on new adoption of smartphones and replacement purchases by existing owners.

Symbian uses the term "ecosystem" complementors (e.g. Northam, 2006). Different categories of licenses and partner relationships exist; the major categories include:

- System integrators or "licensees" (phone manufacturers) that integrate externally sourced and internally developed hardware and software to create new devices (i.e. handsets) for sale to end users. ${ }^{8}$

- $\quad C P U$ vendors work to make sure that Symbian OS is compatible with their latest processors.

- Other hardware suppliers provide drivers for their respective hardware components.

- User Interface companies. Only the Swedish UIQ Technology AB comprised a separate company, but Symbian user interface development groups existed within both Nokia and NTT DoCoMo.

- Other software developers, sometimes referred to as independent software vendors (ISVs). This included developers of user applications and also middleware components such as databases.

- Consultancies and training centers. Symbian provided licensees a list of certified contract software development companies it called Symbian Competence Centers,

6 As a consequence of its indirect business model, Symbian (unlike Microsoft or Apple) focused its branding efforts on system integrators and made little effort to increase public awareness of the Symbian operating system.

7 The word "community" was sometimes used as an alternative, but "ecosystem" was generally preferred since "ecosystem" recognizes the reality that companies have competitive relationships as well as the "friendly" relations implied by the word "community".

8 Within Symbian, handset manufacturers are handled by the Sales division rather than Ecosystem Management, but manufacturers also have full access to all partner information and events. 
including both mobile phone specialists such as the UK-based Teleca and EMCC as well as K3 from Japan, and Symbian-oriented departments within large outsource software suppliers such as Satyam and Wipro. Many of the same companies have also gained accreditation as Symbian Training Partners, in virtue of their experience delivering training courses in Symbian OS development skills.

- Operators, which in most countries are the dominant distribution channel for phones, and also determine what software components are preloaded on phones.

- Enterprise software developers, for cases where a company developed Symbiancompatible software for its employees that use Symbian phones.

In many cases, members of Symbian's ecosystem were also members of competing mobile phone ecosystems, such as those surrounding the Palm OS, Windows Mobile, and more recently plans to develop mobile phones based on Linux by consortia such as the LiMo Foundation and Google's Open Handset Alliance. Unlike with personal computers, most of the largest phone manufacturers and operators were members of three or four competing ecosystems (Figure 2Error! Reference source not found.), as were the largest software vendors. ${ }^{9}$

Symbian's strategy for managing its ecosystem relationships comprised three phases: "ad hoc" (1998-2002), "Platinum Program" (2002-2008), and "Symbian Partner Network" (2008present).

\subsection{Phase 1: An ad hoc Ecosystem Strategy}

The initial structure and conception of the Symbian ecosystem was heavily influenced by its PDA forebears, and prior to that, the well-known exemplars of PC and other computer ecosystems. 
At the time of Symbian's founding, all three major PDA makers - Psion, Microsoft and Palm — had active programs for attracting third party application software. In fact, the initial Symbian OS carried over the APIs, technical documentation, ecosystem support staff and supply of third party software suppliers that had worked with Psion. Psion had organised a series of Developer Conferences, starting in November 1992 when 10 presentations were given to an audience of around 30 developers (Symbian 2008a), and gradually building up to an audience of about 200 developers at events in 1997. "One of the attractions of Symbian OS for Nokia and Ericsson was the reasonably big set of developers we had built up as Psion," recalled Simon East, first VP of technology for Symbian. Symbian's initial ecosystem strategy thus focused on working with third party software developers.

This strategy is illustrated by Figure 3, taken from a presentation made to a meeting of Symbian's Supervisory Board in April 2002 (Wood 2002). The diagram shows two forms of formalised knowledge transfer to ecosystem members:

- "OCK" is the OEM Customisation Kit, containing Symbian OS and tools;

- "SDK" is the Software Development Kit used by ISVs to create applications and other add-on software.

However, the company soon realised that other potential ecosystem members needed their own specialised support. For this reason, a number of separate partnering programs emerged ad hoc during the period 1998-2002:

- A program for Symbian Competence Centers ${ }^{10}$, announced in February 2000 at the opening of Symbian's Developer Conference in Santa Clara, California (Symbian 2000a);

- A program for Symbian Training Partners (Symbian 2000b); 
- A Symbian Technology Partner program, for companies providing technology solutions (such as multimedia engines or compression modules) to run alongside Symbian OS;

- A Semiconductor Partner program, for companies providing hardware components to phone vendors;

- A Tools Partner program, for providers of compilers, integrated development environments, automated test facilities;

- A Development Partner program, for companies supplying technology into Symbian OS itself;

- A Connectivity Partner program, for companies providing solutions for synchronising and backing up data between mobile devices and desktop computers. ${ }^{11}$

Each of these programs tended to be managed by separate individuals inside Symbian, often in different departments. Each program emerged following a separate motivation. It gradually became clear each program had to meet complex needs, but that each had considerable commonality.

Over the next few years, Symbian's actual ecosystem and the pattern of ecosystem coordination evolved beyond the original Psion-inspired model (as illustrated by Figure 4). In particular, the actual ecosystems relations differed from the earlier conception (shown in Figure 3) in two key ways:

- Many partners were supplying software to phone manufacturers, but needed a greater amount of technical information and software than was contained in the SDKs designed for ISVs; 
- These same partners (termed "Licensee suppliers") needed two-way exchange of software with phone manufacturers, in ways that neither the OCK nor the SDK had envisioned or provided for.

Although Symbian had serious and well-managed programs to manage both phone manufacturers and ISVs from 1998-2002, in retrospect it underemphasized helping those companies that supported the phone manufacturers in creating devices.

\subsection{Phase 2: Symbian Platinum Partners}

Around July 2001 a proposal was created to unify many aspects of the previously separate partnering programs, into a new "Platinum Partner" program. The main differences from the ad-hoc programs that preceded it were:

- A deliberate preference for firms providing technology supplied in devices, rather than software added on afterwards. The "device creation" related partners included not only phone manufacturers (e.g., Nokia), but providers of hardware components (e.g. Texas Instruments and Intel) and those that provided bundled middleware (e.g. Sun and Real Networks) or development tools (e.g. Borland and Metrowerks).

- A desire to rationalise the efforts of running lots of different partner programs, and to obtain benefits of scale through having common development kits, event management, billing systems, and communications systems.

A key aspect of the new program was a new package of software provided to technology suppliers, known as the Development Kit ("DevKit"). This contained considerably more software than in the SDKs provided for ISVs, as well as additional licensing rights, but stopped short of the software and rights available to phone manufacturers. ${ }^{12}$ 
The program was discussed internally for nine months, before being announced in April 2002 (Symbian 2002). Reasons for the delay before launching the program included:

- Internal discussions over the appropriate membership fee for the program. Initially, annual fees of $\$ 15-25 \mathrm{k}$ were proposed. After some time, the concept emerged of a lower rate ( $\$ 5 \mathrm{k})$ for program membership, coupled with a surcharge if a partner wished to license the DevKit;

- A change in Symbian CEOs, when its first CEO, Colly Myers, resigned in February 2002 and was replaced two months later by David Levin.

Several key differences between the first and second phases of the Ecosystem Strategy are emphasised by comparing the previous diagram with Figure 5:

- "Licensee suppliers" were renamed as "partners," and the emphasis on supporting them increased because of their important role in helping create new phones;

- Previously ad hoc support mechanisms from Symbian to different partners were re-organised around the existence of the new DevKit;

- Previously ad hoc exchange of information and software between partners and licensees became governed by contractual terms in the new DevKit License (DKL);

- Symbian put less priority on direct support of ISVs, on the assumption that the task of supporting applications developers would shift to the phone makers and those companies UI systems, which after 2001 were located outside Symbian

Instead of directly supporting ISVs, Symbian's Developer Network program would concentrate on being a hub of support for the developer networks in partner companies, who would in turn support ISVs.

Once the platinum program structure was in place, it grew rapidly: by the end of 2002, it had attracted 100 companies, and nearly 300 by early 2006 . 
Even as the program grew in size, Symbian management felt constant conflict between "quantity" and "quality":

- The "quality" approach involved a preference for the larger companies that seemed most likely to become winners in the Symbian space, or which had special endorsements from Symbian's customers.

- The "quantity" approach followed the principle of "level playing field" - avoiding picking winners, but giving an equal opportunity to small and unknown companies; the idea was that even though a given company might have the best technology of its type at one moment in time, this should not become a reason to imagine that company would remain indefinitely as the leader in its space.

Efforts to provide a "level playing field" came at a cost: the resources required to administer a larger program - keeping track of contacts, preparing and chasing invoices, providing technical support, and running larger partner events.

Other difficulties in running a large partner program were already anticipated at the time the Platinum program was created. In April 2002 an analysis of the partner program (Wood 2002) noted two potential problems. First, there were many firms trying to become partners, but they varied widely in terms of their ability to deliver meaningful products. Secondly, Symbian did not have a large enough technical staff to provide the desired level of support for all possible partners.

For these reasons, a prioritisation scheme was viewed as inevitable, and partners (including potential partners) were internally allocated to different tiers of importance: AA, A, B, and C. The AA partners were 15 companies deemed most critical to Symbian's success, A-level were 50 companies of high significance, the B level were those with at least one internal champion, and the $\mathrm{C}$ level comprised the remainder (Wood 2003). 
Finally, ecosystem members differed significantly in their rights to use Symbian's IP: phone manufacturers had less restriction than partners. Phone manufacturers received all source code to Symbian OS $^{13}$ whereas partners did not receive so-called "Category A" source code that was deemed to be particularly confidential or sensitive. Based on an assumed "huband-spokes" model, partners were only allowed to distribute their changes to selected Symbian OS software to phone manufacturers (at the "hub") rather to another partner. As time passed, it became clear to Symbian management that both of these restrictions hindered the free flow of valuable information and innovation among the ecosystem; both restrictions were eventually removed.

Overall, Symbian maintained an ongoing effort to benchmark the Platinum program: almost every year between 2004 and 2007 there was one (or more) internal review project to seek significant improvements in the partnering programs - involving internal managers and/or external consultants. These projects usually started optimistically - people would say things like "It should be easy to stop wasting effort on the low-value partner engagements and to put more effort onto the high-value partner engagements". But as the review projects progressed, the optimism changed to an acceptance that all the easy optimisations of the program had already been made, and that partnering activity which initially looked low-value was often highly valued by important Symbian stakeholders (key customers, internal strategists, and so on).

\subsection{Phase 3: Symbian Partner Network}

In November 2007, Symbian began developing a new partner program to meet two key objectives: 
- Increase the efficiency of the program operation through the enhanced use of IT, including increased web-based automation of common activities and creation of an improved extranet (called "SDN++") to communicate with ecosystem members;

- Utilise that increased efficiency to lower the price and broaden the reach of the program, particularly with independent software vendors.

The most visible change in the program was a reduction in the annual fee from $\$ 5,000$ to $\$ 1,500$. Part of the cost savings came by eliminating assigned partner managers for each registered partner, with ecosystem members instead supported using extranet-based standard information and (paid) technical support. Symbian also lowered its expectations to a breakeven basis; the Platinum program (conceived at a time when Symbian was losing money) eventually generated a net profit.

The revised program was unveiled on April 29, 2008 to existing ecosystem members at Symbian's semi-annual partner event, when Symbian encouraged its existing partners to migrate to the new program. The program was not announced publicly until July 7, with a concurrent announcement that the Platinum program would be discontinued six weeks later. However, the impact of the revised partner program was clouded by the June 24 announcement that Symbian would become a wholly-owned subsidiary of its primary shareholder, Nokia, and its technology donated to the Symbian Foundation, a new open source software foundation. ${ }^{14}$

\subsection{Assessing Symbian's Evolving Ecosystem Strategy}

By many measures, Symbian's ecosystem strategy could be judged a success. By March 2008, it had attracted 9,282 third-party software applications and in $7 \frac{1}{2}$ years, its operating

14 Such open source foundations were originally created to strengthen the negotiating position of volunteer individual contributors, but Nokia's intended use is deliberately modelled on the Eclipse Foundation, in which the foundation increases legitimacy by providing limited autonomy from its main corporate sponsor (see O’Mahony, 2003; West \& O’Mahony, 2008). 
system had been shipped in 200 million phones, the most in the industry (Symbian 2008b). However, both from inside and outside the company, a contrary argument can be made for several crucial decisions.

Most difficult was the relative priority of application software developers. As part of the Psion PDA (and PC) legacy, Symbian was created with an implicit assumption that the major focus of ecosystem management was working with such independent software vendors. However, in 2002 these ISVs were de-emphasised in favour of device creation partners with creation of the 2002 Symbian Platinum Partners program, and then re-emphasised as a driving motivation for creating the 2008 Symbian Partner Network. Symbian's delay in shifting ecosystem support to device creation probably delayed the availability of the first handsets, while the relative neglect of application vendors after 2002 may have put it at a competitive disadvantage compared to Microsoft and particularly Apple.

Related to this was the crucial distinction between preinstalled and user-installed application software. The former proved essential for differentiating the off-the-shelf capabilities of smartphones from feature phones, while the latter proved to have much smaller demand than initially expected.

Some of the shifts in strategies (in response to unforeseen difficulties) are understandable in the context of the information available to Symbian managers at the time that decisions were made.

First, the assumption that the smartphone ecosystem would be like Psion's PDA ecosystem was fundamentally flawed. The ecosystem turned out to be more complex, and more heterogeneous, than originally assumed. This complexity came in part from the special difficulties in creating high-performance software than runs on comparatively low-powered hardware that is sold in large quantities. It also followed from the separation between the provider of the operating system (Symbian) and the providers of the UI layers (e.g. S60 and 
UIQ). A final source of complexity was the high amount of control (particularly over preinstalled software) exerted by handset makers and network operators, as when operators required restrictions on application software capabilities to reduce the risk of viruses.

Secondly, the process of creating new phones proved significantly harder than was originally expected. Wood (2005) identifies a number of potential pitfalls of mobile phone production, including changes in operating system (or UI) APIs across new releases, problems with third party software reliability and integration, and contractual delays in obtaining rights to distribute such software.

A third factor was that resources for the ecosystem management were limited and had to be self-supporting — particularly until Symbian earned its first profit in 2005. Thus, the partner program was limited to provided services to those partners willing to pay enough money to support the cost of providing those services. These restrictions were gradually reduced through IT-enabled efficiencies, including shifting from paper to "click through" agreements and distributing information via an extranet rather than CD-ROM.

However, Symbian had ongoing debates over the balancing between competing goals such as quantity vs. quality, fairness vs. focus, and personal attention vs. economies of scale. Furthermore, partners often wanted to see as much operating system code as possible — and to have rights to redistribute their modifications (such as those necessary to support their own applications). Against this desire, Symbian had to weigh its desire to maintain trade secrets in the source code and to enforce the restrictions of its software suppliers.

\section{Discussion}

Our study identifies three inherent difficulties for firms leading an open innovation ecosystem: knowing the ecosystem requirements for a product that has yet to be created, prioritising the conflicting needs of heterogeneous ecosystem participants, and balancing the interests of those participants against those of the ecosystem leader. 


\subsection{Cognitive Origins of Ecosystem Strategy}

Prior research on ecosystem strategies has presented stylised explanations of how focal firms can control and manage their ecosystem to best advantage (e.g. Iansiti \& Levien, 2004; Maula et al, 2006). While this may be a desirable and perhaps even feasible steady state goal, our data suggests that finding the path to that state is far from trivial — both due to the complexity of the task and the information sufficiency facing the ecosystem leader.

At best, optimising the performance of an ecosystem built around some complex assembled product requires aligning the interests of a heterogeneous population of ecosystem members and partitioning (or self-assigning) the technical and business responsibilities among those members. Any actor has the choice to participate or not in the ecosystem; for many industries, this choice is influenced by the decision of whether to participate (nonexclusively) in one or more competing ecosystems. Finally, the actual (or prospective) failure of any ecosystem member may cause it to withdraw from an ecosystem, leaving a gap that is may be filled only after a considerable delay.

To this complexity, we add the inherent uncertainties (and unknowability) that come with a new ecosystem around the firm's new platform. These uncertainties will be greater for a new firm, without prior firm-level reputation products or ecosystem experience. They will be even worse for a new-to-the-world technology or product category, where there is no direct precedent (known to any party) for partitioning the business and technical responsibilities across ecosystem partners. A firm without products or an ecosystem will have to make assumptions about what technologies and business relationships it will need to create value. As Alan Roderick, onetime head of the Symbian Platinum Partners summarized it: "In the early days, nobody knew where smartphones were going to go, what they were going to be capable of, or what it would take to make them sell.” 
To use the Mintzberg (1978) formulation, any ecosystem strategy has its intentional and emergent aspects. We suggest that the intended strategy is manifest by the firm's efforts in activities, structures and programs to create and nurture an ecosystem, while the emergent strategy arises from those firms that choose to join the ecosystem (or not), pressures from competing ecosystems and broader changes in demand, technology and market structure.

If a firm enters a market without an existing ecosystem, then where does this ecosystem and the firm's initial ecosystem strategy come from? Our data — and the industry standard practice that influenced our subjects - suggests two possible cognitive heuristics that shape ecosystem formation.

First, the firm (or its managers) will build upon the firm's (or their individual) prior ecosystem experience. Symbian was created by spinning off a Psion business unit, so it is not surprising that the ecosystem strategy were inherited from its parent, as were many the relationships with software developers. IBM's reputation and relationships in mainframes and minicomputers carried over to its personal computer, just as Apple used both its structure and many of its developers from its Macintosh ecosystem to launch one for the iPhone.

Secondly, lacking a large body of formal knowledge on ecosystem management, firms adapt strategies from similar ecosystems. This might be the ecosystem of a direct competitor, or by analogy to other industries that appear to have similar relationships with suppliers, customers and complementors. It is here that the PC ecosystem (particularly the Windows ecosystem) has been extremely influential — whether because of the success of the Windows (perhaps independent of its ecosystem strategy) or because it's a highly visible model that is widely known among IT producers and users alike. ${ }^{15}$

15 Another category of ecosystem - with considerably more variation and experimentation - is that of videogame consoles. However, perhaps due to its unique business model (with royalty payments by complementors to console makers) it does not appear to have been widely copied in other industries. 
Consistent with Prahalad \& Bettis (1986), these inherited heuristics form the dominant ecosystem logic for a firm or even an entire industry. However, both of these simplifying heuristics of experience and exemplars will eventually fall short. Over time, Symbian (like Microsoft) found that the ecosystem required for an advanced mobile phone is different than that for a PDA, with less importance for familiar actors and new actors of crucial importance. Firms depend on feedback from both the ecosystem and also their own market success to fine tune their strategies, but (as with any complex strategy) causal ambiguity makes it difficult to impute the success or failure of a strategy to any one decision (cf. Reed \& Defillipi, 1990).

\subsection{Inherent Tradeoffs in Ecosystem Relationships}

While potential members of an ecosystem may see the choices of ecosystem design as a fait accompli, as a practical matter every ecosystem sponsor faces a series of trade-offs in managing ecosystem relationships. These trade-offs are illuminated by the internal perspective of our study and the access we had to the subject company.

A new firm or business unit will face practical limits of staff and other resources that prevent it from taking all possible actions to increase the value created by the ecosystem. If the ecosystem has a direct competitor (or substitute), it will also face pressures to create as much value as quickly as possible. The pressure to win early adoption and a supply of complements are particularly acute in in the face of network effects that lead to a winner-takeall outcome (cf. Arthur, 1996; Shapiro \& Varian, 1999).

The tradeoffs must be made under conditions of limited resources, time and knowledge of the future include:

Breadth vs. depth. For the same amount of time and money, a sponsor can engage deeply with a small number of important partners - maximising their chance of success — or reach broadly (but superficially) to make sure that no potentially important partner goes unaddressed. 
Prioritisation and tiering. As a practical matter, a heterogeneous distribution of partner importance will mean an unequal division of attention; in fact, most programs seem to adopt two-to-four levels of importance (sometimes with the distinction of the top level of attention not publicly disclosed). But within these tiers are questions of how many partners belong in each category, how much resources belong in each, and the differences in costs and benefits between these categories. Again, the risk of neglecting a partner known to be important must be weighed against missing an unknown one.

Scale. A large program is unlikely to provide the personal attention of a small one; at the same time, certain activities that reach a large audience (such as producing standardised documentation or an online partner infrastructure) require economies of scale to implement.

Customisation vs. standardisation. Programs that are flexible to the need of individual partner are the most effective but least efficient; scale both makes standardisation possible as with the effort necessary to create a software development kit — and, in effect, makes it an imperative for supporting all but the most elite partners.

A final reality of ecosystem design is winning the loyalty and attention of partners that are members of multiple competing ecosystems. This is a long-standing issue in the videogame consoles, where the availability of key games (such as sports games from Electronic Arts) are believed essential to the successful launch of a new console. In the mobile phone arena, these divided loyalties apply not only to software developers, but also component manufacturers, system integrators (i.e., handset makers) and operators.

\subsection{Conflicts of Control vs. Complement Supply}

Our study focuses on a particular subclass of ecosystem: that organised to provide complements that increase the value of a specific technology platform (cf. Bresnahan \& Greenstein, 1999). Prior research has emphasised that the third party provision of 
complements for such systems depends on a technical modularity that enables partitioning of the task between firms (Baldwin \& Clark, 2000; Steinmueller, 2003).

However, the mere existence of technical modularity does not mean that it will be possible (or practical) for such complements to be produced: exploiting that modularity requires a combination of codified and tacit knowledge. For electronic components, potentially codified knowledge will include pin specifications and timing diagrams; for software or web services, it will be application programming interfaces.

That information is not costless to codify: in the case of Symbian, the company consistently struggled to allocate sufficient resources to work on software development kits. ${ }^{16}$ A short-term expedient is the person-to-person transfer of knowledge from the creator to the complementor on an ad hoc basis, a less expensive option for a small number of complementors but prohibitively expensive for a large number. ${ }^{17}$

Even if the information is codified, the sponsor faces a difficult choice of how widely to distribute the information and under what intellectual property restrictions. As with other information goods, such information can be costlessly and exactly replicated (Shapiro \& Varian, 1999). That information can be quite valuable to potential or existing competitors, whether in providing insights into the trade secrets behind the system implementation or in allowing emulation and access to the platform's complements (as when Linux became a lowcost imitation Unix that supplanted the original).

However, the platform owner cannot anticipate all possible complements that independent third parties might produce, and - even if it is aware of all complements - accurately

16 Partners and ISVs frequently complained that Symbian's technical documentation and developer tools compared poorly to that available from Microsoft. Despite a series of "documentation catch-up" projects to improve both the quantity and quality of tools and documentation, the criticism continued.

17 Providing the source code implementing a system is a third way of documenting software APIs (although it is no replacement for full design documentation) - one that contains significant trade secret risks for proprietary software, but has become widely used in the past decade with the increasing adoption of open source software. 
anticipate their prospective value to the platform. Restricting the flow of information to potential complementors will delay their production of complements, reduce the resources available for enhancing value, and (at the extreme) can either cause them to fail or discourage them from trying. This concern was articulated by multiple informants from Symbian who were involved in ecosystem management across all three phases.

The problem of controlling information versus enabling complements is part of a broader range of control trade-offs faced by platform owners. In open source software, control must be traded off against adoption, and also against participation in the process of producing that software (West, 2003; West \& O’Mahony, 2008). Here we extend this general trade-off of control vs. participation to the production of complements.

\subsection{Future Research}

There are inherent limitations as to the generalisability from a single case (in this case, a business ecosystem). The Symbian ecosystem is somewhat different from that for Windows Mobile, and significantly different from other mobile phone and computing ecosystems. Ecosystem relationships are considerably simpler in an industry where there is only one major class of complement such as with videogames, an industry where the degree of variation between firms and successive console generations cries out for a systematic study of ecosystem management.

In the tradition of Baldwin and Clark (2000) and others, this work suggests further research as to the interdependence of the technical and economical relationships within an ecosystem. The Symbian ecosystem suggests that the technical structure is more enduring than the business structure. A piece of add-on software may initially be created as a complementary product provided independently to users by its developer, but in mobile phones such complementary software often become software components that are later integrated as part of the value chain. What influence does an ecosystem leader play in 
developing and cultivating such potential value-adding components? How can we predict the difference in the value creation when a complement (adopted by a few) becomes an integrated component (provided to many)? And does this generalise to ecosystems beyond mobile phones where users have search or use difficulties acquiring complements - or to ecosystems where a small number of parties (here manufacturers and operators) play a disproportionate role in product distribution?

Since Symbian was launched, the practice of ecosystem management appears to have become better understood and more mature, with new examples such as mobile phones and videogame consoles as additional exemplars beyond the PC. Will this reduce the problem of a dominant logic for a new ecosystem that force strategies to fit a single well-known exemplar? Or will it merely shift the definition of the dominant logic for ecosystem management?

Finally, the existence of ecosystems with multiple leaders (such as Microsoft and Intel or Nokia and Symbian) suggests a broader problem of defining and operationalising ecosystem leadership. While all firms may have some influence within their portion of an ecosystem, is there a bright line distinction between leaders and followers within an ecosystem? Can a firm be a "little bit" a leader? Is leadership subjectively construed by outcomes, or is it possible to identify through objective metrics the leader(s) of a given ecosystem? 


\section{REFERENCES}

Amit, Rafael and Zott, Christoph (2001); "Value Creation in e-Business." Strategic Management Journal, 22, 493-520.

Arthur, W. B. (1996), "Increasing Returns and the New World of Business," Harvard Business Review, 74, 100-109.

Baldwin, Carliss Y. \& Kim B.Clark (2000). Design Rules, Vol. 1: The Power of Modularity. Cambridge, Mass.: MIT Press.

Bresnahan, Timothy F., Greenstein, Shane. (1999). "Technological competition and the structure of the computer industry," Journal of Industrial Economics 47, 1-40.

Campbell-Kelly, Martin, (2003). From airline reservations to Sonic the Hedgehog: a history of the software industry. Cambridge, Mass.: MIT Press.

Canalys (2008). "Smart mobile device shipments hit 118 million in 2007, up 53\% on 2006," press release, February 5, URL: http://www.canalys.com/pr/2008/r2008021.htm

Chesbrough, Henry W. (2003) Open Innovation, Boston: Harvard University Press.

Cusumano, Michael A. (2004). The Business of Software. New York: Free Press.

Dodgson, Mark and Gann, David and Salter, Ammon (2006). "The role of technology in the shift towards open innovation: the case of Procter \& Gamble," R\&D Management, 36, 3, 333-346.

Eisenhardt, K. M. (1989) "Building Theories from Case Study Research,” Academy of Management Review 14, 532-550.

Gawer, Annabelle \& Henderson, Rebecca (2007). Platform owner entry and innovation in complementary markets: evidence from Intel. Journal of Economics and Management Strategy, 16, 1-34.

Iansiti, Marco and Roy Levien (2004). The Keystone Advantage: What The New Dynamics of Business Ecosystems Mean for Strategy, Innovation, and Sustainability. Boston: Harvard Business School Press.

Johnson, Stephen (2003) "Systems integration and the social solution of technical problems in systems integration," in Prencipe, Andrea, Andrew Davies and Mike Hobday, eds., The Business of Systems Integration, Oxford: Oxford University Press.

Kawasaki, Guy (1990) The Macintosh way, Glenview, Ill.: Scott, Foresman.

Maula, Markku, Thomas Keil and Jukka-Pekka Salmenkaita (2006) "Open innovation in systemic innovation contexts," in Henry Chesbrough, Wim Vanhaverbeke, and Joel West, eds., Open Innovation: Researching a New Paradigm. Oxford: Oxford University Press, pp. 241-257.

Mintzberg, H. (1978). "Patterns in strategy formation," Management Science, 24, , 934-948.

Normann, Richard and Rafael Ramirez (1993), "From value chain to value network: designing interactive strategy," Harvard Business Review, 71 65-77. 
Northam, Phil, ed. (2006). How Smartphones Work: Symbian and the Mobile Phone Industry, Chichester, UK: Wiley.

O’Mahony, Siobhán (2003), “Guarding the commons: How community managed projects protect their work". Research Policy; 32, 1179-1198.

Porter, Michael E. (1985) Competitive Advantage: Creating and Sustaining Superior Performance, New York: Free Press.

Prahalad, C. K. and Richard A. Bettis (1986), "The Dominant Logic: A New Linkage between Diversity and Performance," Strategic Management Journal, Vol. 7, No. 6, pp. 485-501.

Prencipe, Andrea, Andrew Davies and Mike Hobday, eds. (2003). The Business of Systems Integration, Oxford: Oxford University Press.

Reed, Richard and Robert J. Defillippi, (1990), "Causal Ambiguity, Barriers to Imitation, and Sustainable Competitive Advantage," Academy of Management Review, 15 (1), 88-102.

Reger, Rhonda K. and Anne Sigismund Huff. (1993)."Strategic Groups: A Cognitive Perspective," Strategic Management Journal, 14, 103-123

Shapiro, C., Varian, H.R. (1999). Information rules: a strategic guide to the network economy. Boston, Mass.: Harvard Business School Press.

Steinmueller, W. E, (1996). “The U.S. Software Industry: An Analysis and Interpretive History," in Mowery, David C., ed., The International Computer Software Industry: A Comparative Study of Industry Evolution and Structure. New York: Oxford University Press, pp. 15-52.

Steinmueller, W. E. (2003). "The Role of Technical Standards in Coordinating the Division of Labour in Complex System Industries", in A. Prencipe, A. Davies, and M. Hobday (eds.): The Business of Systems Integration, Oxford: Oxford University Press. Symbian 2000a. "New global alliance formed around Symbian to create innovative smartphones and communicators," press release, February 15, URL: http://www.symbian.com/news/pr/2000/pr20003103.html

Symbian 2000b. "Symbian announces worldwide training initiative and European DevExpo to support next generation software development," press release, August 21, URL: http://www.symbian.com/news/pr/2000/pr20003117.html

Symbian 2002. "Symbian opens its source code to third party software and hardware developers," press release, April 22, URL: http://www.symbian.com/news/pr/2002/pr20022995.html Symbian 2008a, "Symbian @ 10: History of Symbian," URL: http://tenyears.symbian.com/timeline.php Symbian 2008b. "Symbian reports first quarter results for 2008," press release, May 20, URL: http://www.symbian.com/news/pr/2008/pr20089950.html 
Symbian 2008c. "New Symbian Partner Network to fuel development on Symbian OS," press release, July 7, URL: http://www.symbian.com/news/pr/2008/pr200810039.html Tasker, Martin (2000).“A New EPOC,” Chapter 1 of Professional Symbian Programming: Mobile Solutions on the EPOC Platform, Wrox Press.

Teece, D. (1986). "Profiting from technological innovation: Implications for integration, collaboration, licensing and public policy," Research Policy 15, 285-305.Vanhaverbeke, Wim (2006) “The Inter-organizational Context of Open Innovation," in Henry Chesbrough, Wim Vanhaverbeke, and Joel West, eds., Open Innovation: Researching a New Paradigm. Oxford: Oxford University Press, pp. 205-219.

West, Joel (2003). “How Open is Open Enough? Melding Proprietary and Open Source Platform Strategies," Research Policy 32, 1259-1285.

West, Joel. (2006). "Does Appropriability Enable or Retard Open Innovation?” In Henry Chesbrough, Wim Vanhaverbeke, and Joel West, eds., Open Innovation: Researching a New Paradigm, Oxford University Press, Oxford, 109-133.

West, Joel and Siobhán O’Mahony (2008). “The Role of Participation Architecture in Growing Sponsored Open Source Communities," Industry \& Innovation, 15, Wood, David (2002). "Symbian Developer Expo 2002 - in context" internal presentation, Symbian Ltd., London, April 2002.

Wood, David (2003). "Partnering goals, 1H 2003" internal document, Symbian Ltd., London, January 2003.

Wood, David (2005) Symbian for smartphone leaders: principles of successful smartphone development projects, Chichester, UK: Wiley, 2005.

Yoshizawa, Masafumi, Yuichi Ichikawa and Yurin Kogetsu (2006). "Expansion of "MOAP” Software Platform for Mobile Terminals," NTT DoCoMo Technical Journal, 8 15-18 (2006).

Zeman, Eric (2008) “1.15 billion Mobile Phones Sold in 2007,” InformationWeek.com, 25 January, URL: http://www.informationweek.com/blog/main/archives/2008/01/115_billion_mob.html 


\section{Figures AND TABLES}

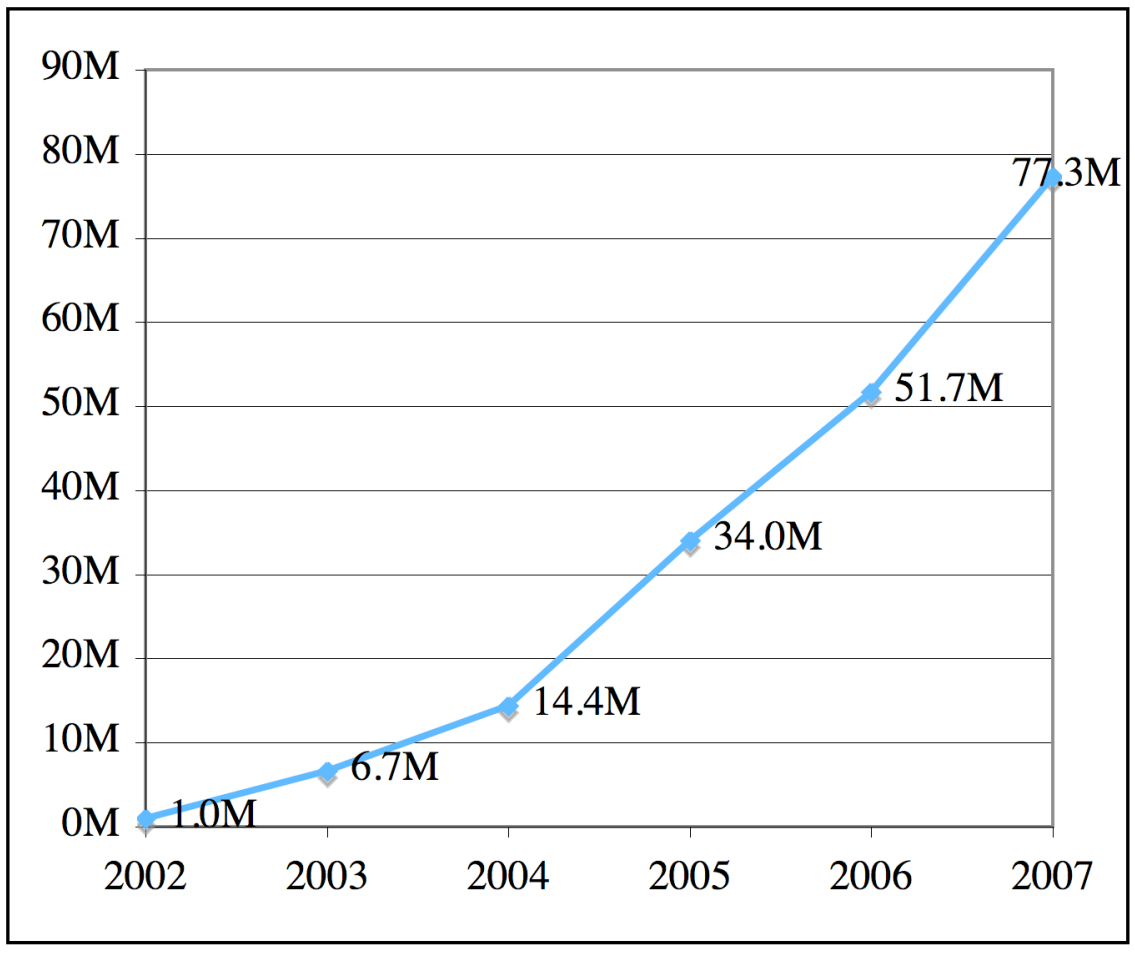

Figure 1: Annual sales of Symbian OS phones (millions) 


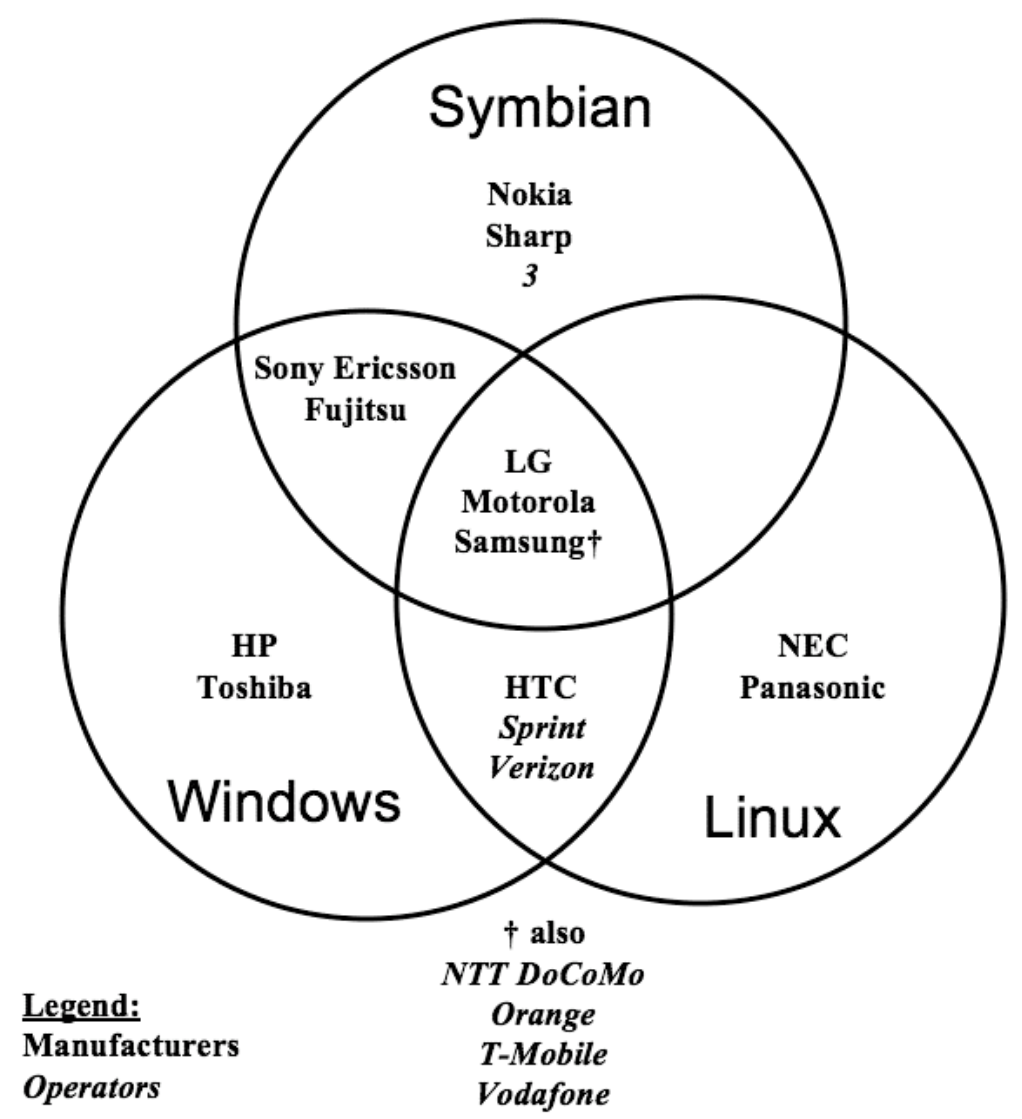

Source: Symbian, Windows: currently shipping devices, as reported by Symbian.com and Microsoft.com

Linux: current members of LiMo Foundation, Open Handset Alliance

Figure 2: Overlapping membership of Symbian, Windows, Linux ecosystems

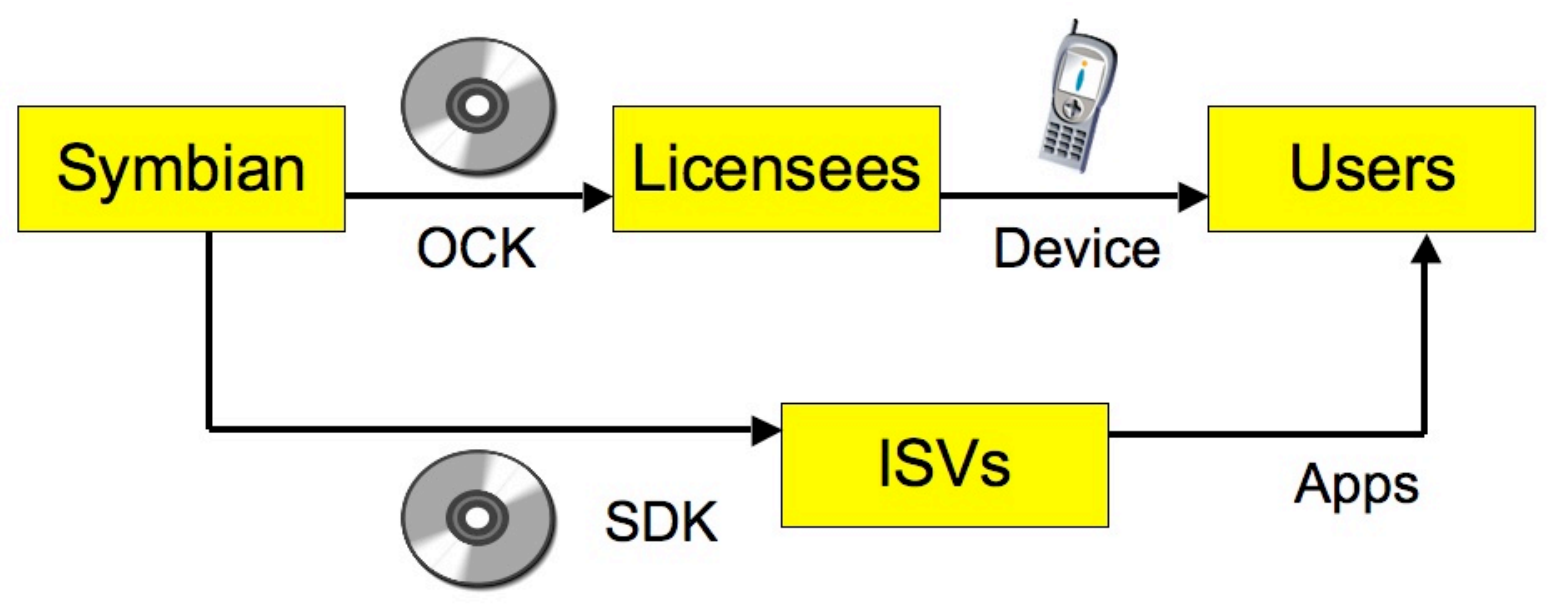

Source: Wood (2002)

Figure 3: Symbian's ecosystem concept as of 1998 


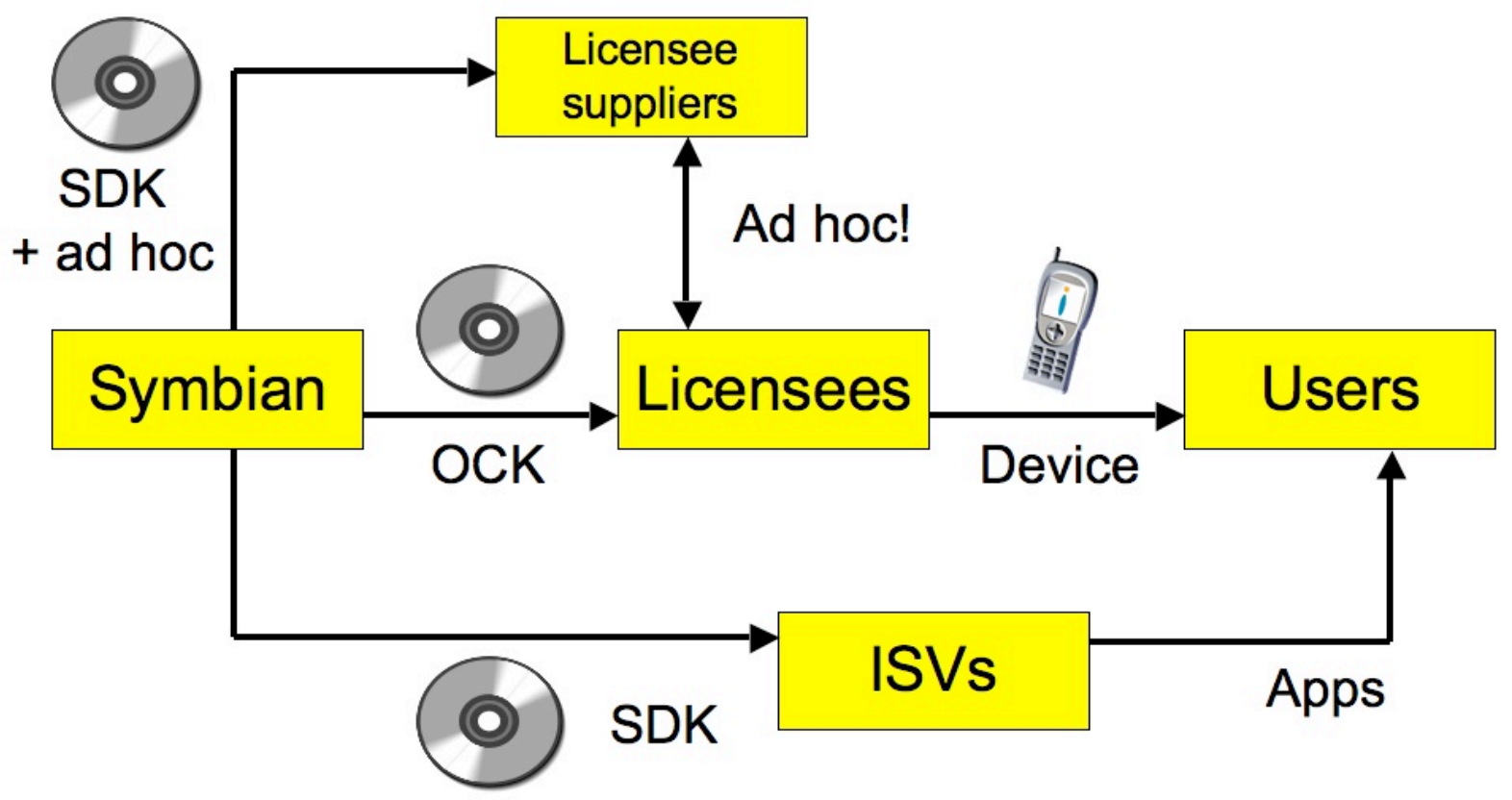

Source: Wood (2002)

Figure 4: Symbian's ecosystem concept ca. 2000

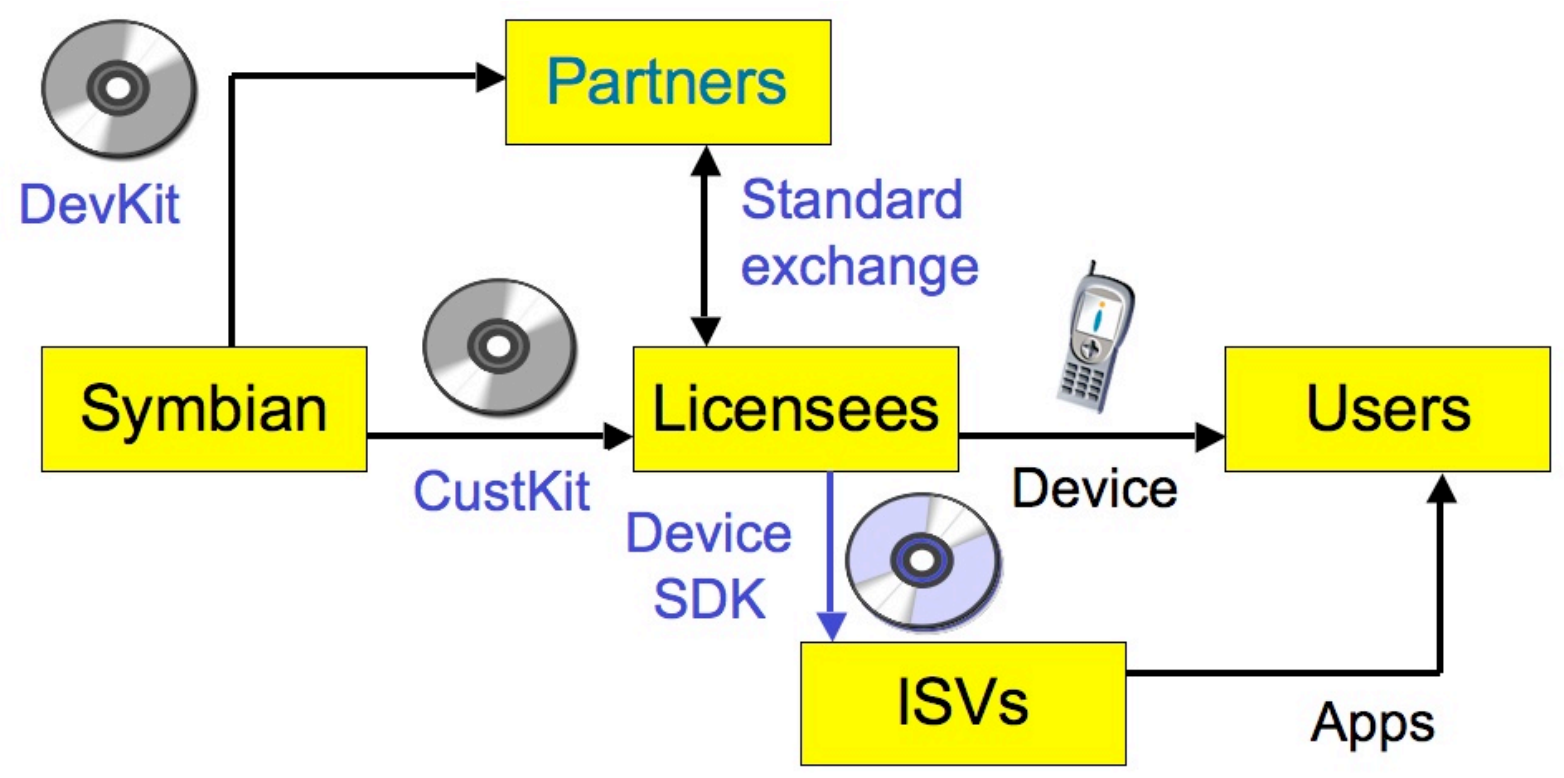

Source: Wood (2002)

Figure 5: Symbian's ecosystem concept as of 2002 
Date

1994

1996

June 1997

June 1998

October 1998

April 1999

June 1999

Feb. 2000

Aug. 2000

Sept 2000

June 2001

Oct. 2001

Nov 2001

April 2002

December 2002

Oct. 2003

November 2003

Feb. 2004

July 2004

Nov. 2006

Nov. 2006

Oct. 2007

March 2008

June 2008

July 2008

Aug. 2008
Event

Psion begins developing a 32-bit operating system, later known as EPOC

Nokia ships Series 9000 Communicator, its first PDA phone, using software licensed from Geoworks

Psion ships Series 5 PDA based on EPOC operating system

Symbian Ltd. founded by Psion PLC, Nokia Oy and Ericsson AB

Motorola pays \$17.9 million to acquire 23\% stake in Symbian Ltd.

Symbian acquires Ericsson's Mobile Application Lab, which later becomes UIQ Technology AB

Symbian holds first conference in London for developers and other ecosystem members

Symbian holds second developer conference in Silicon Valley

Psion announces plans (later cancelled) to spinoff Symbian shares in public offering

Ericsson ships R380, first Symbian OS phone

Nokia ships its first Symbian OS phone, Nokia Communicator 9210

Sony and Ericsson combine mobile phone divisions into U.K.-based joint venture

Nokia announces plans to license Series 60 user interface to other firms

Symbian launches Symbian Platinum Partner Program, a revised ecosystem relations program

Fujitsu releases first Symbian-enabled phone for Japanese market

Motorola sells Symbian shares to Nokia and Psion for £57 million (\$93 million)

NTT DoCoMo licenses Symbian OS for distribution by its phone suppliers

Psion announces plans to sell entire $31 \%$ stake in Symbian to Nokia for $£ 135$ million (\$251 million)

Psion and Symbian sell shares to Nokia, Sony Ericsson, Matsushita, and Siemens for $£ 188$ million

Symbian handset shipments reach 100 million

Symbian agrees to sell UIQ Technology AB to Sony Ericsson

Motorola agrees to buy $50 \%$ of UIQ Holdings from Sony Ericsson

Symbian handset shipments reach 200 million

Nokia announces plans to buy out remaining $52.1 \%$ of shares for $€ 264$ million ( $\$ 410$ million)

Symbian 3rd ecosystem program launched: the Symbian Partner Network

Symbian Platinum Partner program discontinued

Table 1: Key dates for Symbian ecosystem 


$\begin{array}{llcccc}\text { Company } & \text { HQ } & \mathbf{1 9 9 8} & \mathbf{1 9 9 9} & \mathbf{2 0 0 2} & \mathbf{2 0 0 6} \\ \text { Psion } & \text { UK } & 40 \% & 30.7 \% & 26.6 \% & \\ \text { Nokia } & \text { Finland } & 30 \% & 23.1 \% & 20.0 \% & 47.9 \% \\ \text { Ericsson } \dagger & \text { Sweden } & 30 \% & 23.1 \% & 20.0 \% & 15.6 \% \\ \text { Sony Ericsson } & \text { UK } & & & & 13.1 \% \\ \text { Matsushita } & \text { Japan } & & & 8.4 \% & 10.5 \% \\ \text { Samsung } & \text { Korea } & & & 5.0 \% & 8.5 \% \\ \text { Siemens } \dagger \dagger & \text { Germany } & & & & \\ \text { Motorola } & \text { US } & & 23.1 \% & 20.0 \% & \end{array}$

Sources: News coverage, Symbian website

Notes:

$\dagger$ Ericsson assigned its handset business to the Sony Ericsson joint venture in 2001

$\dagger \dagger$ Siemens remains a Symbian shareholder, but sold its handset business to BenQ in 2005

Table 2: Shareholders of Symbian Ltd. 